\title{
Estimating the haul-out population size of a colony of northern elephant seals Mirounga angustirostris in Mexico, based on mark-recapture data
}

\author{
María de la Concepción García-Aguilar ${ }^{1,3, *}$, Enrique Morales-Bojórquez ${ }^{2}$
}

\author{
${ }^{1}$ Instituto Politécnico Nacional, Centro Interdisciplinario de Ciencias Marinas, Av. IPN s/n, Colonia Playa Palo de Santa Rita, \\ Ap Postal 592, CP 23000 La Paz, Baja California Sur, Mexico \\ ${ }^{2}$ Instituto Nacional de la Pesca, Laboratorio de Dinámica de Poblaciones del Pacífico Norte, CRIP_La Paz, \\ Carretera a Pichilingue Km 1 s/n, CP 23020 La Paz, Baja California Sur, Mexico \\ ${ }^{3}$ Present address: Centro de Investigación Científica y de Estudios Superiores de Ensenada, \\ Km 107 carretera Tijuana-Ensenada, CP 22830 Ensenada, Baja California Sur, Mexico
}

\begin{abstract}
We have estimated the haul-out population size (total number of females) of the northern elephant seal Mirounga angustirostris from Isla San Benito del Oeste, Mexico, during the 2001/2002 breeding season. We used mark-recapture data and a method of maximum likelihood supported in a binomial probability density function. Because the number of females on land is not constant during the breeding season, we used 3 different estimations: 1 before the peak of female abundance, another near the peak, and 1 after the peak. An additional estimation was computed using the 3 samples within a joint binomial distribution. The haul-out population size estimated with the joint binomial distribution was 761 females, with a confidence interval from 712 to 818 females $(p<0.05)$. The proximity of the 3 Islas San Benito have caused almost all censuses reported in the literature to show the total counts of all categories of sex and class for all 3 islands together. This study provides the first estimate of the total haul-out population size of $M$. angustirostris from one of the Islas San Benito. From the historical trends of abundance for this species, we can assume an increase at the Isla San Benito del Oeste between 1950 and 1980, but cannot detect any change in abundance between 1980 and 2001.
\end{abstract}

KEY WORDS: Northern elephant seal $\cdot$ Mark-recapture $\cdot$ Haul-out population size Resale or republication not permitted without written consent of the publisher

\section{INTRODUCTION}

Marine mammals have been an important commercial fishery resource and different species are harvested or hunted, i.e. bowhead whales Balaena mysticetus (Punt \& Butterworth 1999), Atlantic harp seal Pagophilus groelandicus (Stenson et al. 2002), or northern elephant seal Mirounga angustirostris (Le Bouef \& Laws 1994). After the extensive hunting in the 19th and early 20th centuries, the northern elephant seal was declared extinct, but in the early 1910s a small group was found at Isla Guadalupe (Bartholomew \& Hubbs 1960). Because the northern elephant seal and Isla
Guadalupe were declared under protection by both the American and Mexican governments, the population size has shown a notable recovery. Stewart et al. (1994) reported, during 1991, a total population size of 127000 individuals. To obtain the needed data, different techniques of stock assessment have been used for marine mammals. In cetaceans, the use of the line-transect method and capture-recapture based on photoidentification are the most common (Barlow 1995, Calambokidis \& Barlow 2004). For pinnipeds, the most frequent method is the use of direct counting (Boyd et al. 1996). In both, mark-recapture experiments have been used (Hammil et al. 1992, 1998, Whitehead 2001). 
There is a great deal of information on the population size and trends of abundance of the northern elephant seal colonies of California, but data from Mexican colonies are scarce. We do not have enough evidence of the trends (Stewart et al. 1994), because we do not know the historic variations of their population size. Because of the annual cycle of the species (the entire population is not ashore all at once), the most satisfactory manner to estimate the population size is to use an approximation of the total number of females during the breeding season or pup production (McCann 1985, Boveng et al. 1988). The breeding season of the northern elephant seal is in winter, and the female distribution has a marked seasonal pattern, with a peak in January (Le Boeuf et al. 1972). In studies where mark-recapture data were available, the estimators assumed lognormal distribution (Smith et al. 1999), binomial distribution (Whitehead 2001), or multinomial distribution (Hilborn 1990), and the use of different density functions to obtain the best accuracy in the abundance estimation (see Hilborn \& Mangel 1997). We have estimated the haul-out population size (total number of females) of Mirounga angustirostris that arrived at Isla San Benito del Oeste using a likelihood model based on a binomial distribution. In this way, we wanted to minimize bias and maximize the precision of the estimation.

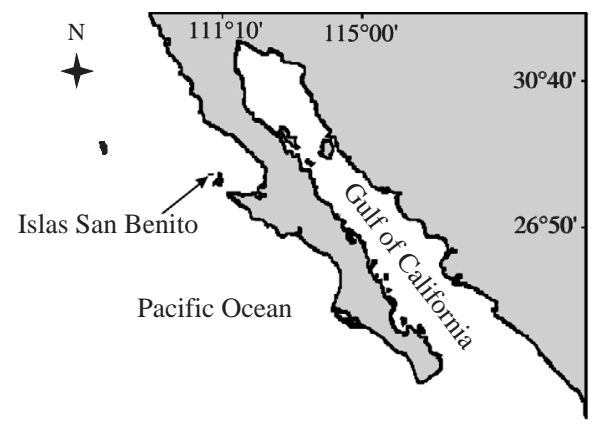

San Benito del Oeste San Benito del Centro San Benito del Este

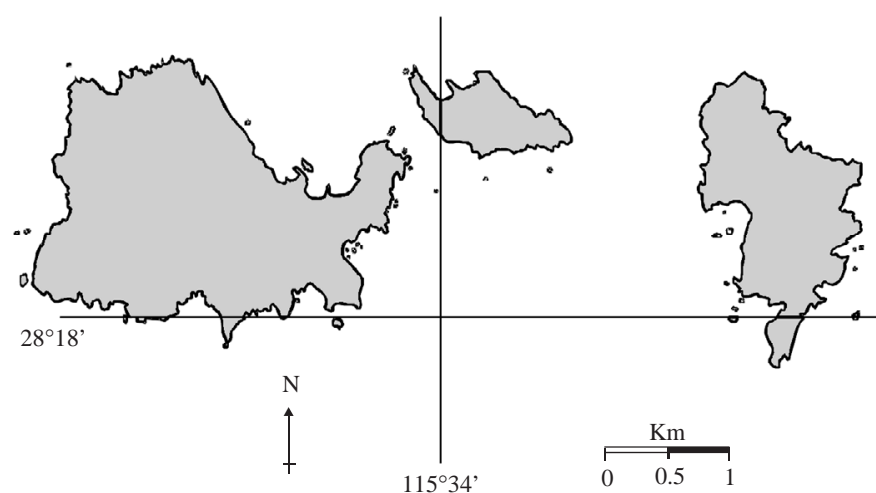

Fig. 1. Mirounga angustirostris. Study area in the Mexican Pacific

\section{MATERIALS AND METHODS}

Field work was done from 19 December 2001 to 18 February 2002. The study area was the northeastern region of Isla San Benito del Oeste $\left(28^{\circ} 18^{\prime} \mathrm{N}, 115^{\circ} 22^{\prime} \mathrm{W}\right)$ (Fig. 1). Here, there are 13 beaches where the elephant seals Mirounga angustirostris arrived for haul-out and breeding. During the field work, on only 7 of these beaches did the females form groups. At the peak of breeding season about $50 \%$ of females on the island congregated on these 7 beaches. We marked females on these beaches on both flanks with an individual code using hair dye (Le Boeuf \& Peterson 1969). The marking began at the start of the field season and continued until no unmarked females were found. We tried to mark each female on the day of arrival to follow each individual systematically throughout its stay on the island (García-Aguilar 2004). During the breeding season, we marked 350 females. Daily counts were made in the study area to obtain data on the number of females marked, and once a week we made a count of the total island to determine the total number of females. Because the number of females on land is not constant during the breeding season, we used, for the analysis, the maximum number of marked females counted in the study area in a single day. This was done by making 3 censuses of the whole island: (1) 1 before the local peak, (2) another near the peak, and (3) 1 after the peak (the peak was defined as the maximum number of females on land). Thus, we performed 3 different experiments of recapture in the study area (Table 1).

The estimation of haul-out population size was computed using the binomial probability density function. When we used binomial probability, we did not use a deterministic approach, because the binomial probability is not necessarily a symmetrical distribution. We analyzed the data assuming that the recapture is an event of presence or absence; in this way, the spatial distribution of females at the island was not considered normally distributed (see Appendix 1 for details). Instead of using the deterministic model (i.e. Hart \& Gorfine 1997, Lowry 1999, Smith et al. 1999, Forcada \& Aguilar 2000), we used the following maximumlikelihood method:

Table 1. Mirounga angustirostris. Counts of northern elephant seal females at Isla San Benito del Oeste during the 2001/2002 breeding season. $\delta$ : number of individuals in the sample size; $\eta$ : number of marked females recaptured

\begin{tabular}{|lrcc|}
\hline Sample & Count date & $\delta$ & $\eta$ \\
\hline $\mathrm{a}$ & 9 Jan & 489 & 150 \\
$\mathrm{~b}$ & 16 Jan & 718 & 184 \\
$\mathrm{c}$ & 23 Jan & 672 & 221 \\
\hline
\end{tabular}




$$
\begin{gathered}
\ln L(\eta \mid \delta, \lambda)=\sum_{i=1}^{\delta} \ln (i)-\left[\sum_{i=1}^{\eta} \ln (i)+\sum_{i=1}^{\delta-\eta} \ln (i)\right]+ \\
\eta \ln (\lambda)+(\delta-\eta) \ln (1-\lambda)
\end{gathered}
$$

where $\delta$ is the number of individuals in the sample size, $\eta$ is the number of marked individuals recaptured, and the proportion $(\lambda)$ of elephant seals that are marked is $\phi / N$, where $\phi$ is the maximum number of marked females counted ( $\phi=225$ females), and $N$ represents the haul-out population size, which was estimated when Eq. (1) was maximized. We estimated 3 different $N$-values with their confidence intervals for each census. However, because we had multiple observations and these were independent of one another, we used a joint binomial distribution and analyzed 701 hypotheses about the value of $N$, where minimum and maximum $N$ were 300 and 1000 individuals, respectively, with increases of 1 individual per hypothesis. The joint estimator was:

$$
\ln L\left(O_{1}, O_{2}, \ldots O_{n}\right)=\sum_{i=1}^{n} \ln L\left(O_{i}\right)
$$

where $O_{i}$ represents the independent observations defined as $\ln L\left(\eta_{n} \mid \delta_{n}, \lambda_{n}\right)$. The difference among independent observations is the number of marked individuals recaptured, and in this case the $\lambda$ value was estimated when the joint distribution was maximized (Haddon 2001).

To estimate the confidence intervals, we used the likelihood profile (Venzon \& Moolgavkor 1988, Hilborn \& Walters 1992, Hilborn \& Mangel 1997), because it can be used to determine confidence intervals for the parameters either jointly or individually. The confidence intervals for $n$ parameters were estimated based on the $\chi^{2}$ distribution with $m$ degrees of freedom (Zar 1974). For a single parameter $p$, the confidence interval is defined as all values of $p$ that satisfy the inequality (Polacheck et al. 1993) as:

$$
2\left[L\left(Y \mid p_{\text {est }}\right)-L(Y \mid p)\right]<\chi_{1,1-\alpha}^{2}
$$

where $L\left(Y \mid p_{\text {est }}\right)$ is the log likelihood of the most likely value of $p$ and $\chi_{1,1-\alpha}^{2}$ are the values of the $\chi^{2}$ distribution with $1 \mathrm{df}$ at a confidence level of $1-\alpha$. Thus, the $95 \%$ confidence interval for $p$ encompasses all values of $p$ that are twice the difference between the log likelihood and the log likelihood of the best estimate of $p$, which is <3.84 (Kimura 1981, Polacheck et al. 1993).

\section{RESULTS}

The estimations of haul-out population size and confidence interval (CI) for independent census samples were: Sample a: $L=0.039, N=733$ females $(\mathrm{CI}=646$ to 842, p < 0.05), Sample b: $L=0.034, N=878$ females
$(\mathrm{CI}=782$ to $994, \mathrm{p}<0.05)$, and Sample c: $L=0.032, N=$ 684 females $(\mathrm{CI}=620$ to $760, \mathrm{p}<0.05)$. The likelihood profiles for the samples are in Fig. 2. The estimation showed the variation as a function of $\eta$ and $\delta$ values (Table 1). It was difficult to choose the best profile. The difference between minimum and maximum estimations was 194 individuals. Moreover, the profiles and estimations of confidence intervals for Samples a and c overlapped, though the likelihood value in Sample a was greater. The uncertainty in haul-out population size cannot be solved with a single independent sample. The sample size $(\delta)$ showed an increase from December to January and a decrease from January to February. Over time, the recaptures $(\eta)$ increased, and in the third sample the individuals recaptured were almost all of the marked individuals (Table 1).

The haul-out population size estimated with a joint binomial distribution was 761 females (CI $=712$ to 818 , $\mathrm{p}<0.05)$ and $L=4.22 \times 10^{-7}$. The likelihood profile includes the 3 independent samples (Fig. 3). The objec-

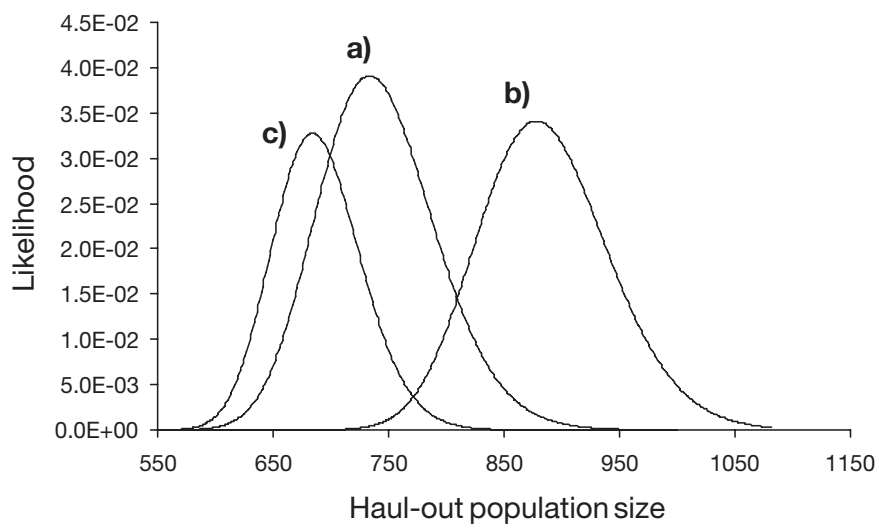

Fig. 2. Mirounga angustirostris. Likelihood profiles of haulout population size for independent samples $(\mathrm{a}, \mathrm{b}, \mathrm{c})$ of $\delta$ and $\eta$ values

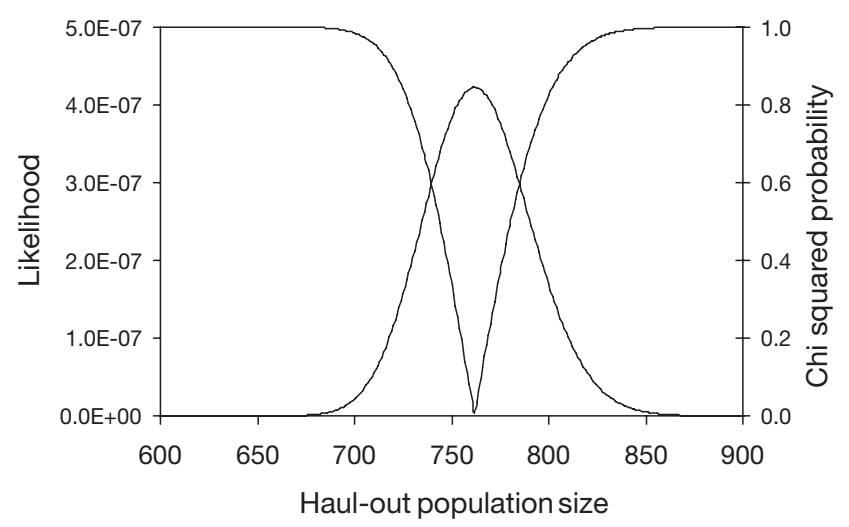

Fig. 3. Mirounga angustirostris. Likelihood profile of haul-out population size for joint binomial distribution (solid line) and confidence intervals defined by $\chi^{2}$ distribution 
tive function was maximized using 3 different sample sizes and recaptures. This estimator is useful when females have been marked and recaptured over nonuniform and nonrandom spatial and temporal scales, so that the probability of recapturing an individual depends on its movement. As a consequence, the assumptions of normality and standard methods are not valid. This result is near the estimation computed with Sample a, but with less uncertainty in the CI.

\section{DISCUSSION}

The most common way to estimate the population size in pinnipeds is to use pup counts, but sometimes it is difficult to obtain a good count when groups are at high densities (Rothery \& McCann 1987). Another way to estimate population size is to use the haul-out population size, because this could reflect the general status of a colony. This study provides the first estimate of the total haul-out population size of Mirounga angustirostris from one of the Islas San Benito. We used the binomial distribution, because it is commonly used in mark-recapture data, where a discrete number of individuals are analyzed (Hilborn \& Mangel 1997), and because this distribution does not assume a 'bellshaped curve' of the data. Galimberti \& Sanvito (2001) published an interesting review about empirical models that assumed a normal distribution of arrival of southern elephant seal Mirounga leonina females. They showed that assumptions regarding the shape of the arrival and departure processes are modeled by a symmetric, accumulative normal distribution according to Rothery \& McCann (1987). The main advantage of their model is that it is easily converted into biologically meaningful parameters. However, they observed tails longer than expected, so that the assumptions of the Gaussian model could result in a bias in the estimations of these parameters (Chen \& Fournier 1999). When we used the binomial distribution, we considered 2 principal advantages. The first was that the parameters were estimated by numerical optimization of an appropriate likelihood function, and the likelihood function had a well-defined maximum, within the range of feasible parameter values. The second advantage was related to the use of different samples of the same population considering a joint binomial distribution, so the objective function used the total number of samples available, reducing the bias and variance in comparison with assumptions of deterministic approaches of normal distribution (Haddon 2001). When the deterministic models were computed, the main source of error was measured in the confidence intervals of the abundance estimates. Our approach shows more advantages in comparison with the Chap- man or Petersen method (Hammil et al. 1992, 1998, Galimberti \& Sanvito 2001, Stenson et al. 2002).

When we analyzed the computations for each sample, we observed a large uncertainty in the estimation of females at Isla San Benito del Oeste. If we used the minimum and maximum values estimated from the likelihood profiles, the difference was from 684 to 878 females. When we analyzed the estimated values in Sample b, it represented the number of females near the peak with 878 females $(\mathrm{CI}=782$ to 994 , $\mathrm{p}<0.05)$, and we noted that this value was greater than the estimation of 761 females $(\mathrm{CI}=712$ to $818, \mathrm{p}<0.05)$ computed with joint binomial distribution. We believed that if only 1 count is obtained near the maximum peak of the breeding season, the data would overestimate the abundance of females, because the joint distribution expressed in Eq. (2) increases its performance when the samples increase in number. The samples are independent, and the estimations were different (Fig. 2); however, the best estimation is shown in Fig. 3. It corresponds to the joint distribution. In Fig. 2 there is great uncertainty about the haul-out population size. Effectively, we concentrated our efforts on counting marked females around the peak of the breeding season (Table 1), so that we would obtain data on when the main quantity of females were on the island. With mark-recapture data, we have the advantage that the recaptured animal is not dead and can be identified many times, giving the technique much more potential power. The main problems could be poorly marked animals, changing marks, and a range of factors producing what is known as heterogeneity, which biases population estimates downward and occurs when some animals are more likely to be recaptured than others. Such differences among individuals could result from their movement patterns, their behavior, or for other reasons (Whitehead 2003). Although the heterogeneity is associated with field work, its effect increases when estimators with normal distribution are used, i.e. the Petersen estimator (Whitehead 2003). We believe that our estimation with joint binomial distribution improves calculations of the haul-out population size of northern elephant seals because it uses 3 different samples (Fig. 3).

The Islas San Benito had an important role in the recovery of the northern elephant seal. The history of the species includes an intensive hunting period during the 19th century, so that by the early 20th century the species was declared extinct. In the early 1910s, a group was found at Isla Guadalupe (<150 individuals), and some years later, in 1918, a group was found at Islas San Benito. During 1938, the first evidence of reproduction from Isla Guadalupe was reported in those islands (Bartholomew \& Hubbs 1960). The total population size in 1957 was estimated at 13000 indi- 
vidual residents at Isla Guadalupe, Islas San Benito, and the Channel Islands (Bartholomew \& Hubbs 1960). Unfortunately, the development of the San Benito colony was not followed systematically, and it is now difficult determine if in the last decades the colony has increased.

Because of the proximity of the 3 Islas San Benito and the interchange of animals (M. C. García-Aguilar unpubl. data), San Benito del Oeste could be taken as a part of a major colony, the San Benito colony. Under this consideration, almost all censuses reported in the literature show total counts for the 3 islands together (Stewart et al. 1994). In addition, the censuses were made after the local season peak, and no correction factors were used. If we take the data of Bartholomew \& Hubbs (1952) and Rice et al. (1965), who reported total elephant seals counted at San Benito del Oeste (all categories of sex and class) as 183 animals (February 1950) and 622 animals (February 1965), and Gisiner et al. (1980), who reported 212 females in February 1980, and use the correction factor determined by García-Aguilar (2004), the estimated haulout population size for each of those years was 174, 512 and 728 females. This correction factor was estimated using demographic data collected during 2 breeding seasons at Isla San Benito del Oeste, and it was based on the Rothery \& MacCann model (1987). Because in our estimations we calculated the haul-out population size as 761 females and although we have incomplete information about historic haul-out population sizes and densities of Mirounga angustirostris, we can assume an increase at Isla San Benito del Oeste between 1950 and 1980, but cannot detect any change in abundance between 1980 and the date of our study. We have made a recent estimation of the number of females of $M$. angustirostris at the Islas San Benito. We do not know if the haul-out population size is stable or if it is increasing. This study must be continued to compare the trends in abundance over time.

Acknowledgements. We thank F. Galimberti and S. Sanvito for their help during the field work. Special thanks to F. Galimberti, who provided useful comments on an early draft, to D. Aurioles-Gamboa for his financial support, and to Ellis Glazier for editing the English-language text. We are grateful the constructive comments from 3 reviewers. The field work was done with official permissions of the Mexican government (Off. No. SGPA/DGVS 8628, Ext. No. DOO.02-0291).

\section{LITERATURE CITED}

Barlow J (1995) The abundance of cetacean in California waters. Part I. Ship survey in summer and fall of 1991. Fish Bull (Wash DC) 93:1-14

Bartholomew GA, Hubbs CL (1952) Winter population of pinnipeds about Guadalupe, San Benito, and Cedros Islands, Baja California. J Mammal 33:160-171
Bartholomew GA, Hubbs CL (1960) Population growth and seasonal movements of the northern elephant seal, Mirounga angustirostris. Mammalia 24:313-324

Boveng PD, DeMaster D, Stewart B (1988) Dynamic response analysis. III. A consistency filter and application to four northern elephant seal colonies. Mar Mamm Sci 4:210-222

Boyd IL, Walker TR, Poncet J (1996) Status of southern elephant seals at South Georgia. Antarct Sci 8:237-244

Calambokidis J, Barlow J (2004) Abundance of blue and humpback whales in the eastern north Pacific estimated by capture-recapture and line transect methods. Mar Mamm Sci 20:63-85

Chen Y, Fournier D (1999) Impacts of atypical data on Bayesian inference and robust Bayesian approach in fisheries. Can J Fish Aquat Sci 56:1525-1533

Forcada J, Aguilar A (2000) Use of photographic identification in capture-recapture studies of Mediterranean monk seals. Mar Mamm Sci 16:767-793

Galimberti F, Sanvito S (2001) Modeling female haul-out in southern elephant seals (Mirounga leonina). Aquat Mamm 27:92-104

García-Aguilar MC (2004) Breeding biology of the northern elephant seal (Mirounga angustirostris) at the Isla San Benito del Oeste, eastern Pacific, Mexico. Aquat Mamm 30:289-295

Gisiner R, Condit R, Landino S, Le Boeuf BJ (1980) Report of a Scripps Institute of oceanography expedition to Baja California islands February 11-22, 1980. University of California, Santa Cruz, CA

Haddon M (2001) Modeling and quantitative methods in fisheries. Chapman-Hall, Boca Raton, FL

Hammill MO, Stenson GB, Myers R (1992) Hooded seal (Cystophora cristata) pup production in the Gulf of St Lawrence. Can J Fish Aquat Sci 49:2546-2550

Hammill MO, Stenson GB, Myers R, Stobo WT (1998) Pup production and trends of the grey seal (Halichoerus grypus) in the Gulf of St. Lawrence. Can J Fish Aquat Sci 55: 423-430

Hart MA, Gorfine KH (1997) Abundance estimation of blacklip abalone (Haliotis rubra). II. A comparative evaluation of catch-effort, change-in-ratio, mark-recapture and diver-survey methods. Fish Res (Amst) 29:171-183

Hilborn R (1990) Determination of fish movement patterns from a tag recoveries using maximum-likelihood estimators. Can J Fish Aquat Sci 47:635-643

Hilborn R, Mangel M (1997) The ecological detective: confronting models with data. Monographs in Population Biology. Princeton Academic Press, Princeton, NJ

Hilborn R, Walters C (1992) Quantitative fisheries stock assessment: choice, dynamics and uncertainty. ChapmanHall, New York

Kimura DK (1981) Standardized measures of relative abundance based on modeling log (CPUE), and the application to Pacific ocean perch (Sebastes alutus). J Cons Int Explor Mer 39:211-218

Le Boeuf BJ, Laws RM (1994) Elephant seals: population ecology, behavior, and physiology. University of California Press, Los Angeles, CA

Le Boeuf BJ, Peterson RS (1969) Social status and mating activity in elephant seals. Science 163:91-93

Le Boeuf BJ, Whiting RJ, Gantt RF (1972) Perinatal behavior of northern elephant seal females and their young. Behavior 43:121-156

Lowry SM (1999) Counts of California sea lion (Zalophus californianus) pups from aerial color photographs and from the ground: a comparison of two methods. Mar Mamm Sci 15:143-158

McCann ST (1985) Size, status, and demography of southern 
elephant seal (Mirounga leonina) populations. In: Ling JK, Bryden MM (eds) Studies of sea mammals in south latitudes. South Australian Museum, Northfield, p 1-17

Polacheck T, Hilborn R, Punt A (1993) Fitting surplus production models: comparing methods and measuring uncertainty. Can J Fish Aquat Sci 50:2597-2607

Punt A, Butterworth DS (1999) On assessment of the Bering-Chukchi-Beaufort seas stock of bowhead whales (Balaena mysticetus) using a Bayesian approach. J Cetacean Res Manage 1:53-71

Rice DW, Kenyon KW, Lluch D (1965) Pinniped populations at Islas Guadalupe, San Benito, and Cedros, Baja California, in 1965. Proc S Diego Soc Nat Hist 14:74-84

Rothery P, McCann TS (1987) Estimating pup production of elephant seals at South Georgia. Symp Zool Soc Lond 58: 211-223

Smith TD, Allen J, Clapham PS, Hammond PS and 8 others (1999) An ocean-basin-wide mark-recapture study of North Atlantic humpback whales (Megaptera novaeangliae). Mar Mamm Sci 15:1-32
Stenson GB, Hammill MO, Kingsley CS, Sjare B, Warren WG, Myers R (2002) Is there evidence of increased pup production in northwest Atlantic harp seals, Pagophilus groelandicus? ICES J Mar Sci 59:81-92

Stewart BS, Yochem PK, Huber HR, DeLong RL, Jameson RJ, Sydeman WJ, Allen SG, Le Boeuf JB (1994) History and present status of the northern elephant seals population. In: Le Boeuf BJ, Laws RM (eds) Elephant seals: population ecology, behavior and physiology. University of California Press, Los Angeles, CA, p 29-48

Venzon DJ, Moolgavkor SH (1988) A method for computing profile-likelihood-based confidence intervals. Appl Stat 37:87-94

Whitehead H (2001) Analysis of animal movement using opportunistic individual identifications: applications to sperm whales. Ecology 82:1417-1432

Whitehead H (2003) Sperm whales: social evolution in the ocean. University of Chicago Press, Chicago, IL

Zar JH (1974) Biostatistical analysis. Prentice-Hall, Englewood Cliffs, NJ

Appendix 1. Differences between Petersen estimator and binomial probability function

Having tagged and resighted tags in a new sample, a deterministic answer can be found with the Peterson estimator (Haddon 2001):

$$
\frac{n_{1}}{X}=\frac{m}{n} \text { then } X=\frac{n_{1} n}{m}
$$

where $n_{1}$ is the number of tags in the population, $n$ is the subsequent sample size, $m$ is the number of tags recaptured, and $X$ is the population size. An alternative estimate adjusts the counts of the second sample to allow for the fact that in such cases we are dealing with discrete events:

$$
X=\frac{n_{1}(n+1)}{m+1}
$$

Like all good estimators, it is possible to estimate the standard error (SE) of this estimate and thereby generate $95 \%$ confidence intervals around the estimated population size:

$$
\mathrm{SE}=\sqrt{\frac{n_{1}^{2}(n+1)(n-m)}{(m+1)^{2}(m+2)}}
$$

If the Peterson estimator is used, we are assuming that SE is normally distributed, i.e. the subsequent sample size $(n)$ is assumed to have a normal distribution, a mean of 0 , and the variance $\sigma^{2}$. Instead of using the deterministic equations, a good alternative would be to use maximumlikelihood methods to estimate the population size $X_{\text {, }}$ using the binomial probability density function. The binomial probabilities were implemented as log likelihoods for the calculations:

$$
P\{m \mid n, p\}=\left[\frac{n !}{m !(n-m) !}\right] p^{m}(1-p)^{(n-m)}
$$

where $p$ represents a proportion of individuals that are marked. Log-transforming the component terms:

$$
\ln \left[p^{m}(1-p)^{(n-m)}\right]=m \ln (p)+(n-m) \ln (1-p)
$$

and

$$
\ln \left[\frac{n !}{m !(n-m) !}\right]=\ln (n !)-\{\ln (m !)+\ln [(n-m) !]\}
$$

noting that:

$$
\ln (n !)=\sum_{i=1}^{n} \ln (i)
$$

we obtain the log-likelihood function expressed in Eq. (1)
Editorial responsibility: Otto Kinne (Editor-in-Chief), Oldendorf/Luhe, Germany
Submitted: October 10, 2003; Accepted: April 21, 2005 Proofs received from author(s): July 1, 2005 